International Mathematical Forum, Vol. 8, 2013, no. 26, 1287 - 1293

HIKARI Ltd, www.m-hikari.com

http://dx.doi.org/10.12988/imf.2013.35105

\title{
A Common Unique Fixed Point Theorem for Expansive Type Mappings in S-Metric Spaces
}

\author{
Prabha Chouhan \\ Scope College of Engineering Bhopal (M.P.), India \\ prabhachouhan@yahoo.com \\ Neeraj Malviya \\ NRI Institute of Information Science and Technology, \\ Bhopal (M.P.) India \\ maths.neeraj@gmail.com
}

Copyright (c) 2013 Prabha Chouhan and Neeraj Malviya. This is an open access article distributed under the Creative Commons Attribution License, which permits unrestricted use, distribution, and reproduction in any medium, provided the original work is properly cited.

\begin{abstract}
In present paper, we prove a common unique fixed point theorem for expansive mappings in $S$-metric space which correspond to contractive mapping of theorem 1 in [10].
\end{abstract}

Mathematics Subject Classification: 47H10, 54H25

Keywords: Expansive mapping, $S$-metric space, Fixed point

\section{Introduction and Preliminaries}

The advancement and the rich growth of fixed point theorems in metric spaces have important theoretical and practical applications. The development has been tremendous in the last three decades. Although the concept of a fixed point theorem may appear as an abstract notion in metric spaces, it has remarkable influence on applications such as the theory of differential and integral equations [2], the game theory relevant to the military, sports and 
medicine as well as economics [3]. In 89, Gahler [5,6] introduced the notion of 2-metric spaces while Dhage [1] intoduced the concept of $D$-metric spaces. Later on, Mustafa and Sims [11] showed that most of the results concerning Dhage's $D$-metric spaces are invalid. Therefore, they introduced a new notion of generalized metric space, called $G$-metric space. Very recently in [7], Sedghi, Shobe and Aliouche have introduced the notion of an $S$-metric space and proved that this notion is a generalization of a $G$-metric space and a $D^{*}$ metric space. Also, they have proved some properties of $S$-metric spaces and some fixed point theorems for a self-map on an $S$-metric space. An interesting work that naturally rises is to transport certain results in metric spaces and known generalized metric spaces to $S$-metric spaces. In this way, some results have been obtained in $[7,8,9]$. In this paper, we present common unique fixed point theorem for expansive map which is defined in [4] for rational inequality. Now we recall some notions and lemmas which will be useful later.

Definition 1.1. Let $X$ be a nonempty set. An $S$-metric on $X$ is a function $S: X^{3} \rightarrow[0, \infty)$ that satisfies the following conditions, for each $x, y, z, a \in X$.

1. $S(x, y, z) \geq 0$

2. $S(x, y, z)=0$ if and only if $x=y=z$

3. $S(x, y, z) \leq S(x, x, a)+S(y, y, a)+S(z, z, a)$

The pair $(X, S)$ is called an $S$-metric space.

Immediate examples of such $S$-metric spaces are:

(1) Let $X=R^{n}$ and $\|$. $\|$ a norm on $X$, then $S(x, y, z)=\|y+z-2 x\|$ $+\|y-z\|$ is an $S$-metric on $X$.

(2) Let $X$ be a nonempty set, $d$ is ordinary metric on $X$, then $S(x, y, z)=$ $d(x, z)+d(y, z)$ is an S-metric on $X$.

Lemma 1.2. [7]: In an $S$-metric space, we have $S(x, x, y)=S(y, y, x)$.

Definition 1.3. [7]: Let $(X, S)$ be an $S$-metric space.

(1) A sequence $\left\{x_{n}\right\}$ in $X$ converges to $x$ if and only if $S\left(x_{n}, x_{n}, x\right) \rightarrow 0$ as $n \rightarrow \infty$. That is for each $\varepsilon>0$ there exists $n_{0} \in N$ such that for all $n \geq n_{0}$, $S\left(x_{n}, x_{n}, x\right)<\varepsilon$ and we denote this by $\lim _{n \rightarrow \infty} x_{n}=x$.

(2) A sequence $\left\{x_{n}\right\}$ in $X$ is called a Cauchy sequence if for each $\varepsilon>0$, there exists $n_{0} \in N$ such that $S\left(x_{n}, x_{n}, x_{m}\right)<\varepsilon$ for each $n, m \geq n_{0}$. 
(3) The $S$-metric space $(X, S)$ is said to be complete if every Cauchy sequence is convergent in $X$.

Lemma 1.4. [7]: Let $(X, S)$ be an $S$-metric space. If the sequence $\left\{x_{n}\right\}$ in $X$ converges to $x$, then $x$ is unique.

Lemma 1.5. [7]: Let $(X, S)$ be an $S$-metric space. If the sequence $\left\{x_{n}\right\}$ in $X$ converges to $x$, then $\left\{x_{n}\right\}$ is a Cauchy sequence.

Lemma 1.6. [7]: Let $(X, S)$ be an $S$-metric space. If there exist sequences $\left\{x_{n}\right\}$ and $\left\{y_{n}\right\}$ such that $\lim _{n \rightarrow \infty} x_{n}=x$ and $\lim _{n \rightarrow \infty} y_{n}=y$, then $\lim _{n \rightarrow \infty} S\left(x_{n}, x_{n}, y_{n}\right)=S(x, x, y)$.

\section{Expansive map}

Definition 1.7. [7]: Let $(X, S)$ be an $S$-metric space. A map $F: X \rightarrow X$ is said to be expansive if there exists a constant $L>1$ such that $S(F(x), F(x), F(y)) \geq L S(x, x, y)$ for all $x, y \in X$.

Example 1.8. [7]: Let $X=R$ and $S$ is define by $S(x, y, z)=|x-z|+$ $|y-z|$ where $x, y \in R$. Then $(X, S)$ is an $S$-metric space. Define a self map $T$ on $X$ as follows $T x=\beta x$ where $\beta>1$ for all $x \in X$. Clearly $T$ is an expansive mapping.

\section{Main Results:}

Theorem 2.1. Let $f$ and $g$ be two surjective self maps on a complete $S$ metric space $(X, S)$ and

$$
\begin{aligned}
S(f x, f x, g y) & \geq \frac{a S(x, x, f x), S(y, y, g y)}{S(x, x, y)}+b[S(x, x, f x)+S(y, y, g y)] \\
& +c S(x, x, y)
\end{aligned}
$$

with $x \neq y$ Where $a, b \geq 0, c>1$. Then $f$ and $g$ have a common unique fixed point in $X$.

Proof: We define a sequence $\left\{x_{n}\right\}$ as follows for $n=0,1,2,3, \ldots$

$$
x_{2 n}=f x_{2 n+1}, \quad x_{2 n+1}=g x_{2 n+2}
$$

If $x_{2 n}=x_{2 n+1}=x_{2 n+2}$ for some $n$ then we see that $x_{2 n}$ is a fixed point of $f$ and $g$. Therefore, we suppose that no two consecutive terms of sequence $\left\{x_{n}\right\}$ are equal. 
Now consider

$$
\begin{aligned}
& S\left(x_{2 n}, x_{2 n}, x_{2 n+1}\right)=S\left(f x_{2 n+1}, f x_{2 n+1}, g x_{2 n+2}\right) \\
& \geq \frac{a S\left(x_{2 n+1}, x_{2 n+1}, f x_{2 n+1}\right) S\left(x_{2 n+2}, x_{2 n+2}, g x_{2 n+2}\right)}{S\left(x_{2 n+1}, x_{2 n+1}, x_{2 n+2}\right)} \\
&+b\left[S\left(x_{2 n+1}, x_{2 n+1}, f x_{2 n+1}\right)+S\left(x_{2 n+2}, x_{2 n+2}, g x_{2 n+2}\right)\right] \\
&+c S\left(x_{2 n+1}, x_{2 n+1}, x_{2 n+2}\right) \\
&=\frac{a S\left(x_{2 n+1}, x_{2 n+1}, x_{2 n}\right) S\left(x_{2 n+2}, x_{2 n+2}, x_{2 n+1}\right)}{S\left(x_{2 n+1}, x_{2 n+1}, x_{2 n+2}\right)} \\
&+b\left[S\left(x_{2 n+1}, x_{2 n+1}, x_{2 n}\right)+S\left(x_{2 n+2}, x_{2 n+2}, x_{2 n+1}\right)\right] \\
&+c S\left(x_{2 n+1}, x_{2 n+1}, x_{2 n+2}\right) \\
& \Rightarrow(1-a-b) S\left(x_{2 n},\right.\left.x_{2 n}, x_{2 n+1}\right) \geq(b+c) S\left(x_{2 n+1}, x_{2 n+1}, x_{2 n+2}\right)[b y \text { Lemma } 1.2] \\
& \Rightarrow S\left(x_{2 n+1}, x_{2 n+1}, x_{2 n+2}\right) \leq \frac{1-(a+b)}{b+c} S\left(x_{2 n}, x_{2 n}, x_{2 n+1}\right) \\
& \Rightarrow S\left(x_{2 n+1}, x_{2 n+1}, x_{2 n+2}\right) \leq K_{1} S\left(x_{2 n}, x_{2 n}, x_{2 n+1}\right) \\
& \text { where } K_{1}=\left[\frac{1-a-b}{b+c}\right]<1 \quad(\text { As a }+2 b+c>1)
\end{aligned}
$$

Similarly we can calculate

$$
\Rightarrow S\left(x_{2 n+2}, x_{2 n+2}, x_{2 n+3}\right) \leq K_{2} S\left(x_{2 n+1}, x_{2 n+1}, x_{2 n+2}\right)
$$

$$
\text { where } K_{2}=\left[\frac{1-a-b}{b+c}\right]<1
$$

and so on

$$
\begin{gathered}
\Rightarrow S\left(x_{n}, x_{n}, x_{n+1}\right) \leq K S\left(x_{n-1}, x_{n-1}, x_{n}\right) \quad \text { for } n=1,2,3 \ldots \\
\qquad \text { where } K=\max \left\{K_{1}, K_{2}\right\} \text { then } K<1 \\
\Rightarrow S\left(x_{n}, x_{n}, x_{n+1}\right) \leq K^{n} S\left(x_{0}, x_{0}, x_{1}\right)
\end{gathered}
$$

Now we shall prove that $\left\{x_{n}\right\}$ is a cauchy sequence. For this for every positive integer $P$, we have 


$$
\begin{aligned}
S\left(x_{n}, x_{n}, x_{n+p}\right) & \leq 2 S\left(x_{n}, x_{n}, x_{n+1}\right)+2 S\left(x_{n+1}, x_{n+1}, x_{n+2}\right)+\ldots \\
& +2 S\left(x_{n+p-2}, x_{n+p-2}, x_{n+p-1}\right)+S\left(x_{n+p-1}, x_{n+p-1}, x_{n+p}\right) \\
& \leq 2 S\left(x_{n}, x_{n}, x_{n+1}\right)+2 S\left(x_{n+1}, x_{n+1}, x_{n+2}\right)+\ldots \\
& +2 S\left(x_{n+p-2}, x_{n+p-2}, x_{n+p-1}\right)+2 S\left(x_{n+p-1}, x_{n+p-1}, x_{n+p}\right) \\
& \leq\left[2 K^{n}+2 K^{n+1}+\ldots+2 K^{n+p-2}+2 K^{n+p-1}\right] S\left(x_{0}, x_{0}, x_{1}\right) \\
& =2 K^{n}\left[1+K+K^{2}+\ldots+K^{p-1}\right] S\left(x_{0}, x_{0}, x_{1}\right) \\
& <\frac{2 K^{n}}{(1-K)} S\left(x_{0}, x_{0}, x_{1}\right)
\end{aligned}
$$

Which implies that $S\left(x_{n}, x_{n}, x_{n+p}\right) \rightarrow 0$ as $n \rightarrow \infty$.

Therefore $\left\{x_{n}\right\}$ is a cauchy sequence in $X$, which is complete space, so $\left\{x_{n}\right\} \rightarrow x \in X$.

Existence of fixed point: Since $f$ and $g$ are surjective maps and hence there exist two points $y$ and $y^{\prime}$ in $X$ such that

$$
x=f y \text { and } x=g y^{\prime}
$$

Consider,

$$
\begin{aligned}
S\left(x_{2 n}, x_{2 n}, x\right) & =S\left(f x_{2 n+1}, f x_{2 n+1}, g y^{\prime}\right) \\
& \geq \frac{a S\left(x_{2 n+1}, x_{2 n+1}, f x_{2 n+1}\right) S\left(y^{\prime}, y^{\prime}, g y^{\prime}\right)}{S\left(x_{2 n+1}, x_{2 n+1}, y^{\prime}\right)} \\
& +b\left[S\left(x_{2 n+1}, x_{2 n+1}, f x_{2 n+1}\right)+S\left(y^{\prime}, y^{\prime}, g y^{\prime}\right)\right]+c S\left(x_{2 n+1}, x_{2 n+1}, y^{\prime}\right) \\
& =\frac{a S\left(x_{2 n+1}, x_{2 n+1}, x_{2 n}\right) S\left(y^{\prime}, y^{\prime}, g y^{\prime}\right)}{S\left(x_{2 n+1}, x_{2 n+1}, y^{\prime}\right)} \\
& +b\left[S\left(x_{2 n+1}, x_{2 n+1}, x_{2 n}\right)+S\left(y^{\prime}, y^{\prime}, g y^{\prime}\right)\right]+c S\left(x_{2 n+1}, x_{2 n+1}, y^{\prime}\right)
\end{aligned}
$$

As $\left\{x_{2 n}\right\}$ and $\left\{x_{2 n+1}\right\}$ are subsequences of $\left\{x_{n}\right\}$ as $n \rightarrow \infty,\left\{x_{2 n}\right\} \rightarrow x$, $\left\{x_{2 n+1}\right\} \rightarrow x$.

Therefore

$$
\begin{aligned}
S(x, x, x) & =\frac{a S(x, x, x) S\left(y^{\prime}, y^{\prime}, x\right)}{S\left(x, x, y^{\prime}\right)}+b\left[S(x, x, x)+S\left(y^{\prime}, y^{\prime}, x\right)\right] \\
& +c S\left(x, x, y^{\prime}\right) \quad[\text { by Lemma 1.6] }
\end{aligned}
$$




$$
\begin{array}{lr}
0 \geq(b+c) S\left(x, x, y^{\prime}\right) & {[\text { by Lemma } 1.2]} \\
\Rightarrow S\left(x, x, y^{\prime}\right)=0 & (\text { As } b+c>0) \\
\Rightarrow & x=y^{\prime}
\end{array}
$$

In an exactly similar way we can prove that,

$$
x=y
$$

The fact (2.1.3) along with (2.1.4) and (2.1.5) shows that $x$ is a common fixed point of $f$ and $g$.

Uniqueness: Let $z$ be another common fixed point of $f$ and $g$, that is

$$
f z=z \text { and } g z=z
$$

$$
\begin{aligned}
& S(x, x, z)=S(f x, f x, g z) \\
& S(x, x, z) \geq \frac{a S(x, x, f x) S(z, z, g z)}{S(x, x, z)}+b[S(x, x, f x)+S(z, z, g z)]+c S(x, x, z) \\
& \Rightarrow S(x, x, z)=\frac{a S(x, x, x) S(z, z, z)}{S(x, x, z)}+b[S(x, x, x)+S(z, z, z)]+c S(x, x, z) \\
& \Rightarrow(1-c) S(x, x, z) \geq 0 \\
& \Rightarrow S(x, x, z)=0 \quad(\text { Asc }>1) \\
& \Rightarrow x=z
\end{aligned}
$$

This completes the proof of the theorem 2.1

Corollary 2.2. Let $f$ be surjective self map on a complete $S$-metric space $(X, S)$ and

$$
\begin{aligned}
S(f x, f x, f y) & \geq \frac{a S(x, x, f x), S(y, y, f y)}{S(x, x, y)}+b[S(x, x, f x)+S(y, y, f y)] \\
& +c S(x, x, y)
\end{aligned}
$$

with $x \neq y$ Where $a, b \geq 0, c>1$. Then $f$ has a unique fixed point in $X$.

Proof: If we put $f=g$ in theorem 2.1 then we get above corollary 2.2.

Corollary 2.3. Let $(X, S)$ be an $S$-metric space and $f: X \rightarrow X$ be a surjection. Suppose that there exist a positive integer $n$ and a real number $K>1$ such that

$$
\begin{aligned}
S\left(f^{n} x, f^{n} x, f^{n} y\right) & \geq \frac{a S\left(x, x, f^{n} x\right), S\left(y, y, f^{n} y\right)}{S(x, x, y)}+b\left[S\left(x, x, f^{n} x\right)+S\left(y, y, f^{n} y\right)\right] \\
& +c S(x, x, y)
\end{aligned}
$$

for all $x, y \in X$. Then $f$ has a unique fixed point in $X$. 
Proof: From corollary $2.2 f^{n}$ has a unique fixed point $z$. But $f^{n}(f z)=$ $f\left(f^{n} z\right)=f z$, so $f z$ is also a fixed point of $f^{n}$. Hence $f z=z, z$ is a fixed point of $f$. Since the fixed point of $f$ is also fixed point of $f^{n}$, the fixed point of $f$ is unique.

\section{References}

[1] B.C. Dhage, Generalized metric space and mapping with fixed point, Bull. Cal. Math. Soc. 84(1992), 329-336.

[2] E. Zeidler, Nonlinear Functional Analysis and its Applications. Springer, New York (1989).

[3] K.C. Broder, Fixed point Theorems with Applications to Economics and Game Theory. Cambridge University press, Cambridge (1990).

[4] P. Chouhan and N. Malviya, Fixed point of Expansive Type Mapping in S-metric Spaces, communicated in Fixed Point Theory and Applications.

[5] S. Gahlers, 2-metrische Raume and ihre topologische structure, Math. Nachr, 26, 115-148 (1963).

[6] S. Gahlers, Zur geometric 2-metrische raume, Revue Roumaine Math. Pures Appl. 11, 665-667 (1966).

[7] S. Sedghi, N. Shobe and A. Aliouche, A Generalization of fixed point theorems in S-metric spaces Mat. Vesnik 64,3(2012),258-266.

[8] S. Sedghi and N.V. Dzung, Fixed point theorems on S-metric spaces Mat. Vesnik (2012 accepted paper).

[9] T.V. An and N.V. Dung, Two fixed point theorems in S-metric spaces. Preprint (2012).

[10] Y.C. Paliwal, Fixed point theorem in metric space, Bull. Calcutta Math. Soc. 80 (1988), 205-208.

[11] Z. Mustafa and B. Sims, A new approach to generalized metric spaces. Journal of Nonlinear and convex Analysis 7, 2(2006), 289-297.

\section{Received: June 1, 2013}

